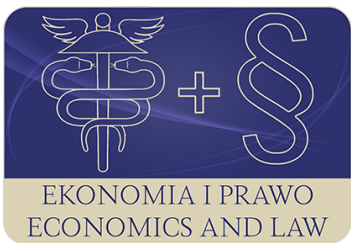

EKONOMIA I PRAWO. ECONOMICS AND LAW

Volume 15, Issue 4, December 2016

p-ISSN 1898-2255, e-ISSN 2392-1625

www.economicsandlaw.pl

ORIGINAL ARTICLE

received 16.06.2016; revised 06.09.2016; accepted 31.12.2016

Citation: Bejger, S. (2016). The specifics of supply chain of medical kits product group in the context of using Enterprise Resource Planning class systems. Ekonomia i Prawo. Ecomomics and Law, 15(4): 419-438. doi:10.12775/EiP.2016.028.

\title{
The specifics of supply chain of medical kits product group in the context of using Enterprise Resource Planning class systems
}

\author{
SYLWESTER BEJGER \\ Nicolaus Copernicus University, Faculty of Economic Sciences and Management, Department \\ of Economics, ul. Gagarina 13A, 87-100 Toruń, Poland \\ 曰sylw@umk.pl
}

\begin{abstract}
Motivation: The article contains proposals of IT solutions supporting the management of selected links in the supply chain of Disposable Medical Kits product group.

Aim: The aim of the article is the analysis of the distinctive features of the supply chain of Disposable Medical Kits product group (later referred to as DMK) in the context of managing such chain by means of IT solutions.

Results: The first part of the article identifies distinctive features of the supply chain for this product group, which are of importance in the context of realizing the goals of social logistics of medical products supplies, as well as from the point of view of optimizing the management of the chain's individual links. The second part of the article is devoted

to presenting proposals of IT solutions supporting the management of supply chain,

whose functionality are implied by the analysis conducted in the first part.
\end{abstract}

Keywords: disposable medical kit; supply chains, ERP II systems; variant configuration; configurable material

JEL: M11; I19; L65; L23; C88

\section{Introduction}

The aim of the article is the analysis of the distinctive features of the supply chain of Disposable Medical Kits product group (later referred to as DMK) 
in the context of managing such chain by means of IT solutions. The problem of an efficient management of the supply chain of that product group is of great importance for the producers and the customers, as well. For the manufacturers it is the case due to very distinct features of the supply and demand for DMK products, which were researched in the paper in details. For the customers it is due the role of the DMK, as a very important medical product, which supplies should be undistorted, prompt and fully fulfilled? Therefore, the in depth study conducted in the paper could be interesting and relevant for the managers on producer side and the managers of a health sector, as well. The research contain original proposition of the IT production model of that particular product group and from that point of view could be interesting as theoretical basis for further development of logistic model for that group. The article, as the first one, identifies the distinctive features of this product group, describes the most important implications of these features for the supply chain, formulates theses on the key factors of management of the chain and proposes certain solutions concerning IT support for the servicing and management of the chain's selected links. It could be regarded therefore as adding some novel knowledge to the topic.

The analysis of supply chain was conducted from the point of view of the manufacturer of the studied product group, yet it has to be emphasized that optimal functioning of this chain is of great significance in the context of social logistics of a healthcare sector.

A medical kit is defined as a set of medical products meant for a specific type of a medical (surgical) procedure. Depending on their use, the following can be distinguished:

- reusable medical set - such as, for instance, a set of surgical tools designed for hip replacement surgery,

- disposable medical kit $(\mathrm{DMK})^{1}$ - for instance, a set of medical products (bandages, surgical drapes, other disposable instruments), designed for angiography (picture 1).

It is assumed that DMKs analyzed are products assembled by the manufacturer and packed into inseparable packages. Assembly process concerns both the materials produced by the manufacturer and purchased from outside suppliers. It should be noted that an outside supplier (trading partner) may be providing both the raw materials for DMK's manufacturer's in house production of components used in DMK and/or finished goods (components) which are part of a DMK. Further in the article, the supplied raw materials and components purchased from an outside supplier will be generally referred to as supplied materials, unless the analysis requires distinguishing between both types of materials.

${ }^{1}$ NAICS 2012 code for medical kits is mostly 339113, however some disposable instruments and kits could have codes from 339112 group (U.S. Census Bureau, 2016). 


\section{Current state of knowledge and methodology of the research}

The research was initiated after very detailed interview with one of the most important manufacturers of medical products in the Polish market. From the very beginning the aim of the research was very general in a sense of answering the questions: how to manage the production of DMK's optimally from the point of view the manufacturer and how to support the logistics management with IT system efficiently. Those questions made the research broad and interdisciplinary, as it had occurred that there were not such comprehensive study in the literature yet. The study utilizes three main strands of concepts and literature sources. For supply chain management in general, there is a huge literature, for the present study Frazell (2002) and Waters (2015) were consider as the most adequate. The big picture of worldwide demand for medical products is outlined in P. M. Parker (2008). The main findings, however, are connected with identified distinctive features of DMK logistics and their connection with particular model of production strategy and product itself, and IT implementation of that models. For production strategy a mass customization (MC) concept was found as very suitable. In that second source of ideas works of Davis (1989, pp. 16-21), Pine et al. (1993, pp. 108-118) and Da Silveira et al. (2001, pp. $1-13)$ can be treated as an introductory to the concept. The bridge between MC and supply chain management was developed in Chandra and Kamrani (2004). As the present work is an application one, the papers of MC application in various industries should be enumerated (home building (Barlow et al., 2003, pp. 134-145), mobile phones (Comstock et al., 2004, pp. 362-372), electronics (Partanen \& Haapasalo, 2004, pp. 213-222) or food industry (McIntosh et al., 2010, pp. 1557-1574). However, for the author's knowledge, there is no direct application of MC strategy to DMK's manufacturing so far. As MC is a production strategy concept only, the equally important for managers is a proposal of an implementation of a model of product in IT system, which model would be coherent with the MC. Our idea was to utilize a Variant Configuration production model on the SAP ERP platform. A background literature on this topic encompasses various sources on ERP systems in general, as Adamczewski (2007), Banaszak et al. (2011) or Simha and Word (2012) but more interesting for the purposes of the research are the sources devoted to implementation of production processes and variant configuration in the SAP ERP system. The most influential are Akhtar (2013) and Blumöhr et al. (2012) The works of Forza and Salvator (2002, pp. 87-98) or Helo et al. (2010, pp. 44-52) deal with practical problems of variant configuration but our work is direct proposal of such an implementation in DMK manufacturing.

Methods of the research was two-fold. At first, an extensive study of actual logistics processes of one of the major domestic manufacturers of medical products was done. Additional information ${ }^{2}$ from the management and market research was accounted for, either. Placing that on the academic background

2 This information was proprietary and confidential in part. 
lead to conclusions (say, economic) of part 3. Integrating this conclusion with a concept of variant configuration model lead to proposal of implementation of DMK's production model in SAP ERP ECC 6.04 system. The model was then configured and tested in a live system.

\section{Distinctive features of DMK product group from the point of view of supply chain}

DMK product group has certain distinctive features which have important implications for managing the supply chain. Below, the features have been identified and discussed in terms of their impact on the potentially required solutions concerning the flow and integration of information.

\subsection{Specific requirements concerning the quality and safety of using particular materials included in a DMK - supplier qualification}

The vendors in a supply chain are qualified according to compliance of the quality and safety regulations in trading medical materials for the material supplied.

Each supplier of an element of a medical kit must possessed the required quality and compliance documents, for instance:

- CE certificate,

- declaration of conformity,

- ISO 13485 certificate,

- product specification, compliant with all the European norms for a given medical product,

- documents certifying compliance with the requirements for microbiological purity,

- documents certifying meeting the requirements for bio compliance.

Within a supply chain one should take into account the terms necessary to gather appropriate documentation and to ensure access to its uniform and upto-date version for all relevant organizational units.

Apart from the formal requirements, a very important role is played by the reproducibility of each material of a medical kit. It should be borne in mind that the manufacturer certifies each medical kit by means of their own CE certificate, thus warranting the safety of using it for the end-user.

Having taken that into consideration, on-going control of the compliance of the supplied material's parameters to the reference should be included within the supply chain for the already qualified suppliers.

\subsection{Wide assortment of product, low repeatability of production}

An important aspect of DMKs is that their production must very often be tailored to the individual (untypical) specification of particular customer. It results in a substantial diversification of the range of products and an enormous 
number of potential specifications of DMKs, which is in parallel with the global trend of SKU proliferation (Frazell, 2002, p. 96). Another direct consequence of such situation are short production's series. The other consequences are significant difficulties with initial cost calculation of the newly-introduced DMKs and effective supply and production planning.

From a point of view of supply chain management, the most important factor here is a limited possibility of keeping inventories of finished goods (DMKs). The reason for that is the fact that the desired specification of new DMKs is created by the customers in an irregular fashion (see: next point), which results in a potentially unlimited number of variants of finished goods which should be kept in storage. Even if the specifications of DMKs differ only in one element of the set (for example, the type of scalpel), it is impossible to simply replace the elements, as DMKs are sterile products, one-time packed. Apart from that, each DMK as a medical product have strict shelf life and expiration date, which limits the possibility of keeping large stocks of finished goods.

\subsection{Specificity of the orders of medical kits}

DMKs constitute a group of products with a very specific segment of customers and the way of purchase. The end-customers are usually healthcare institutions (private or public) capable of performing medical procedures using DMKs, which means medium-size or large ones. The purchase of DMKs in such institutions (or groups of institutions) is most frequently performed in the form of a tender, due to legal regulations (in Poland for instance, in the public healthcare institutions), or because is determined by the economic efficiency of this form of purchase (private healthcare units in many countries). It should be noted that it is usually the manufacturer who supply directly to the end-user, and a selling by the third party is very rare and occurs only in the case of simple DMKs (like, for instance, dialysis kits). What is more, using intermediaries is often a reaction to the order placed by intermediaries themselves as a result of their successful tender bid. Such a mode of sale by the manufacturer has significant consequences, as it is marked by high irregularity of orders. Winning/ losing a tender results in an immediate change in the future demand for a given DMK. A successful tender bid does not, however, have to mean the purchase of $100 \%$ of the contracted volumes of DMKs. Moreover, the purchases of even the same customer could be irregular in terms of DMK's specification, volumes or terms of order's realization. The last consequence is often a short period of time (for, example 1 month) between the selection of the winning tender and the deadline for supplying the customer with the first tranche of the contracted volume of a given DMK. All those factors cause significant difficulties with forecasting of a supply/demand for DMKs (at the level of finished good) and a material requirements planning. 


\subsection{High differentiation of the terms of supply for DMK's components}

A DMK may contain elements (raw materials as well as finished goods, which we name assemblies or components further in a text), whose required supply terms may differ among each other by as much as 2 months. One kit may include materials available to the manufacturer within only 2 weeks, as well as the ones that take 2 or 3 months to be delivered. An element especially prone to the differentiation of supply terms is the chain's reaction to realizing the tender for DMKs containing materials which have not been supplied to the manufacturer previously. As noted above, additional deadlines associated with the supplier's qualification should be taken into consideration in such cases.

Having the abovementioned DMK group's specificities in mind, it can be concluded that optimizing the supply chain of diversified assortment of DMKs should be conducted following two main objectives, fitting into the context of social logistics of healthcare sector:

- secure the fulfillment of customers' needs (in terms of safety, quality and supply terms);

- ensure production's cost-effectiveness while maintaining its high flexibility. Transforming the abovementioned goals into certain recommendations for managing supply chain, it can be pointed out that:

- ongoing quality control of supplied materials and finished products should be carried out;

- the possibility of identifying materials and finished products should be considered at any stage of production and distribution;

- optimal stocks of materials should be maintained from the point of view of present and future demand, a mixture of Contingency Inventory (CI) and Efficient Manufacturing Inventory $(\mathrm{EMI})^{3}$ could be considered;

- purchase orders of the materials should be placed in clear accordance with particular production plans and possible sales forecasts;

- the possibility of keeping part of the needed stock of materials at qualified suppliers storage should be negotiated (elements of SRM model of Extended Supply Chain concept could be utilized);

- buyers/planners should be allowed to place orders for smaller, irregular and properly defined batches of materials;

- the supply chain between DMK manufacturer and the actual supplier of materials should be shortened as much as possible;

- attention should be paid to optimizing the ratio: the volume of materials purchased / the cost of transportation of the order from vendor;

- the unit price (assuming, of course, the supplier's qualification) is the basic criterion of purchase, but alternative qualified supplier of a given material should be secured, which would guarantee shorter delivery time at a possibly higher price.

\footnotetext{
${ }^{3}$ For details on these inventory models see Frazell (2002, p. 94).
} 
The enumerated postulates lead to the following conclusions:

a. the key role is played by planning the demand for DMKs which is not based on historical data, or components' level planning;

b. planning data coming directly from sales units (sales offices) are very important;

c. supplier's information on possible capacity limits (planned downtimes, for example), realistic terms for deliveries and minimum manufacturing lot are of crucial importance (SRM model of cooperation should be considered);

d. effective integration of demand planning with supplies is necessary;

e. high flexibility of purchase organization in terms of reaction is required, and at the same time:

- due to a very differentiated and short-series assortments of products, as well as expiration dates for medical products (low rationality of creating large stocks of finished products);

- reproducibility of components in kits and raw materials in components manufactured in house (the possibility of creating certain stocks of raw materials and typical components). It seems that a more crucial element is flexible and precise planning of the material requirements, which in turn generates purchase requisitions;

f. it is required to consider often freezing batches of materials for quality control and to introduce batch management and very granular serialization.

\section{Proposed IT solutions in DMK supply chain}

When analyzing the economic implications of DMK supply chain (first section of the article), the most crucial issue seems to be, broadly understood, informational integration of all directly involved manufacturer's units (and partly also the units of trading partners-suppliers). The following theses can thus be put forward:

- the key component of DMK supply chain is the chain of information;

- each link of the supply chain should be integrated with the others in the IT system and receive up-to-date and accurate information, as well as generate it;

- each link of the supply chain should acquire the knowledge on internal and external limitations of the supply and production logistics from the IT system;

- a supply chain management based on appropriate IT tools and parametrization of business objects and processes allows for flexible reaction to the market needs.

In terms of IT solutions, taking the abovementioned theses into account, the most crucial element is completing the following tasks:

- effective demand planning for DMKs and/or DMK components which generates planned independent requirements; 
- ensuring access to uniform and up-to-date information for all system users, which means the creation and maintaining of master data;

- appropriate parametrization of master data, such as material master data, bills of materials or routings, which takes into account the specificity of DMK supply chain;

- adopting a proper virtualization of DMK production, bearing in mind appropriate product model and planning strategy;

- linking flexible production scheduling with generating requirements for purchased materials and production orders on the produced materials, taking into consideration the possessed manufacturing capacities;

- the possibility to make quick changes in production schedules and the requisitions and orders linked to them, ability to creating and work with what-if scenarios.

In the following part of the article, we shall point to selected concepts of implementing the production and supply process for DMKs, which we consider crucial to creating a supply chain capable of performing the tasks pointed out in part 1.

The primary assumption should be that the right platform for integrating the supply chain in the discussed case is the ERP II class system. ERP systems focus primarily on intra-company processes and they integrate functional and cross-functional business processes (Simha \& Word, 2012, p. 14). ERP II class system can be identified as one optimizing business processes both internal, and the ones occurring in the company's close environment, by offering ready tools allowing for automation of data exchange with partners along the whole logistic chain ${ }^{4}$. Adopting ERP class system as the primary informational platform guarantees the realization of the postulate of master data uniformity (one source of truth) on the basis of a typical relational database, which is a standard in systems of this type, or on the basis of one of the newly introduced database supporting In-Memory architecture, for example SAP HANA platform. In addition, the system guarantees the integration of data and processes, which is exchange of data within an object or with its surroundings, including the functionality of the production planning module integrated with manufacture resource planning modules (MRP) as well as purchasing ones, which is crucial for DMKs, carried out within informational structure. MRP module is the central module of ERP logistic systems. Manufacture resource planning is one of the most complex areas of plant logistics. The MRP method was introduced to efficiently manage material resources and supply (Banaszak et al., 2011, p. 168). MRP develops the basic production plan leading to the creation of a detailed scheme aimed at supplying raw materials and resources needed for maintaining operations (Waters, 2015, p. 391). For the sake of presenting the discussed concepts, this article shall make use of the solution by SAP AG company - SAP ERP ECC 6.04 integrated system. On the basis of this plat-

${ }^{4}$ Alternative definitions of ERP II class system can be found, for example in Auksztol et al. (2010, p. 9) or Szkoda (2010, p. 11). 
form's solutions, let us assume a general standard of realizing a part of logistic chain from the demand forecast for completed products to production execution (scheme 1).

On the basis of this structure we shall discuss in more detail the proposals for solutions which may facilitate the management of the logistic chain elements for DMKs in terms of realizing the abovementioned desired directions. An element which is of great significance is the independent requirements' planning module. If the manufacturer adopts a planning strategy for the highest level of a bill of material (finished good) then, as known from the previous part, a crucial factor for DMKs is the planning which is not based on historical data, taking into account the chances of realizing individual orders (successful tender) and supply batches for the tenders already won. In order to carry out the planning tasks, one can make use of external modules in relation to the basic ERP system (such as the demand planning module being a part of SAP SCM, which is SAP APO, or the demand planning module by Oracle, Oracle Demantra), as well as use the possibility of generic SOP planning (long-term or flexible planning) in the ERP system standard. It must be emphasized that the problem of effective, midterm planning of sales/demand in the conditions specific for DMKs is a complex issue itself and requires further analysis and proposals for organizational and tool-based solutions (econometric specification of possible planning models). This article shall not attempt to elaborate on it.

In our opinion, the factor of crucial importance for the optimal IT support of DMK supply chain which would ensure the desired results enumerated in the article is proper parametrization of the model of production and the product, as well as all the master data connected with them. As it was pointed out, the primary characteristics of the process of fulfilling demand for DMKs is a wide range of products (with relatively small BOM's variety), the necessity of reacting to customers' individual orders (in terms of specification, amount or deadlines) and necessity of high quality assurance. This observation is in-line with the mass customization concept (Tseng \& Jiao, 1996, pp. 153-156; Da Silveira et al., 2001, pp. 1-13).

For parameters defined in this way, it seems that a variant configuration based on object classification is the optimal solution to adopt for DMKs. We shall present those concepts on the example5 of SAP ERP ECC 6.04 system's functionality.

Variant configuration is an appropriate product model in a situation when the assortment of finished products includes a large number of products of similar bills of material and routings, and the possibility for the customer to individually configure the finished good is highly important. A typical field of its use is, for instance, automotive industry. In the case of DMKs, we can consider

5 The system of object classification and the possibility of using it in variant configuration are available in ERP systems by SAP AG, starting from version R/3, but their popularity has been systematically increasing during the last decade. The source of basic definitions and concepts in terms of variant configuration is the monograph by Blumöhr et al. (2012). 
the product group to be highly coherent with this model. The basic problem in such situations, in a typical implementation of master data, is the necessity to deal with about nm of SKU's master data records, bill of materials (BOM), or routings (task lists), where $\mathrm{n}$ is the number of attributes (product characteristics' values), and $m$ is the total number of characteristics describing finished good. The second issue of standard product's model is low flexibility of reaction of a part of the supply chain in response to the customer's order (the necessity to process the order and deciding if material of required specification is available).

Obviously, an appropriate production scenario (business model) for a product's variant configuration is the MTO (Make to Order) model, which can be further tuned by using scenarios of ATO (Assembly to Order) or CTO (Configure to Order).

When referring to the DMK product group, CTO seems to be the appropriate production scenario. The business model assumes configuration of the finished product at the level of a sales order being entered into the system, on the basis of the customer's specification (using a predefined list of components and the possibility of adding new ones, previously unused)

Variant configuration of material (DMK) is based on using object classification system which is a part of SAP ERP Central Components, and on using the characteristics and classes in the definition of the finished good.

If we are to assume that the manufacturer performs conversion of the production model and DMK products to the CTO model with a variant configuration, the essential stages of the process are:

1. Stage 1 - functional and/or statistical analysis of the range of products and product BOMs in order to distinguish sub-groups of DMK of similar parameters (according, for instance, to the type of medical procedure DMK is used for). Such an analysis leads to introducing the materials (DMKs) into the classification system.

2. Stage 2 - defining the DMK's characteristics and allowed characteristics' values.

3. Stage $3-$ maintain variant classes (classes, in short) by assigning the characteristics to the distinguished classes.

Pictures 2 and 3 exemplify the realization of classification. Picture 2 includes the examples of a feature (characteristic) of DMK (Kompres component of a DMK) along with the values (attributes) of the characteristics (the screenshots contain master data and an extended hierarchy of selected feature)

As it can be seen, the characteristic may be multilevel nested, which offers an enormous number of variants of a given component maintained within one characteristic. The following properties of characteristics are also important for model specification:

- characteristics can have numerical values (points, intervals, calculated) and character values; 
- they may receive 'required characteristics' indicator (for example, each DMK must have packaging of certain type 'packaging' characteristics would receive the 'required' indicator independently of the customer's order).

Picture 3 represents a defined class which groups the characteristics. A class describes a group of objects that have common or similar specifications.

In DMK classification one can use a class object to groups of DMK of similar structure, functions and production technology indicated on the basis of analysis conducted at the first stage.

In picture 3 such a class is MEDSET, containing the listed characteristics. It should be noted that each class belongs to a certain type of classes (in SAP ECC the reserved type for variant configuration is class 300 , whereas for the classifying node the reserved type is 200 or 201 (document)). An important functionality of the classification system is the possibility of linking documentation from the central document management system (Document Management System in SAP ECC) with the class, characteristic of characteristic's value. One can thus link, for instance, certification documents, technical documentation or microbiological research findings with the appropriate object and display them at the right moment (for example, at the stage of configuration DMK to the customer's order).

4. Stage 4-maintaining and/or configuration of master data for configurable materials.

Stage 4 is the key stage of the whole implementation because:

- it defines a material as a representative of a whole variant's class;

- connects the physically existing objects (DMKs) with the classifying system;

- determines the way of planning for a material.

The material for which a variant model is created is called configurable material. In SAP ECC material type KMAT has been reserved for such a material, however, it is enough to simply mark an appropriate checkbox in a basic data 2 view of master data record, to enable its variant configuration (picture 4).

A configurable material is assigned into a pre-defined class (classification view), which means that a given material record is a representative of a potentially big number of DMKs that can be configured for a given class (picture 5). The last parameters of great importance are parameters of MRP group, MRP type and a planning strategy (picture 6). The parameters determine the production model, the way of material resource planning and the details of planning for each level of BOM. A factor of particular attention should be planning strategy, as its appropriate selection allows for planning, for example, for DMK's components only, which seems to have sense taking into account the substantial uncertainty of orders flow for finished products on the one hand, and the repeatability of components and materials in many DMKs on the other.

5. Stage 5 - maintaining bill of material (BOM) and task lists (routings) for configurable DMKs together with dependencies. 
It is the second of the most important stages of preparing a variant configuration for the following reasons:

- it is when so called super BOMs are prepared. Super BOM contains all the parts that might be required to manufacture the configurable material, so it includes all bill of material elements available for a given set of variants. At this stage s super routings are defined as well, which contain the list and order of technological operations (along with their parametrization: times, work centers, keys etc.), as well as necessary PRTs. The super routing contains all the operations that could be needed to manufacture the configurable material. By creating a super $\mathrm{BOM}$, it is worth considering, for the sake of making DMK configuration more flexible, the introduction of the BOM item category R (variable-size item) for materials (components) produced in house For the simple components which differ, for instance, in size only (surgical drape), for which the production process involves only cutting to size and folding, there is no need to define the values of characteristics, as the servicing of variants (different sizes) takes places within the BOM;

- be defining so called dependencies super BOMs and super routings elements are linked with the allowed values of characteristics from a given class.

It should be emphasized that the definitions of dependencies not only allow for basic assigning: the value of a characteristic choice of a super BOM element, but also make the DMK configuration process to be immensely more flexible, as it is possible to introduce logical links between elements of configuration by using logical operators, for instance if a scalpel of type A was selected, then the selection of type B scalpel is excluded, or if X type of needle was selected, then a certain type of syringe should be selected..

The defined dependencies are linked with the super BOM and super routing, which are afterwards marked as 'configurable'.

6. Stage 6- defining configuration profiles. The configuration profiles contain steering and controlling elements for creating variants at the Sales and Distribution level (high-level configuration). They are created for each configurable material.

Stage 6 leads to presenting the target functionality of a configurable product model for DMK, which is the scenario of configuration of DMK at the level of sales order, along with dynamic generation of an order BOM and task list.

The process of customizing a customer's order may start as early as at the request for quotation stage, but generally variant configuration (definition of DMK) is conducted at the point of processing the customer's order (picture 7).

In the transaction of creation a standard order for configurable material, in a correctly defined environment, product configurator allowing for choosing the characteristics' values from the class a given DMK has been assigned to is automatically initiated. In the case we are following, one could choose, for instance, a compress with a RTG thread (as well as other, not necessarily all characteristics of the MEDSET class). If the component was produced 
by the manufacturer in house, the sales office person would be able, by means of dependencies of documents, to check the certifications of the raw materials used in the compress production process (BOM explosion) and checking availability of raw materials. Assuming the correct parametrization of the other master data, such as vendors' master records, source lists or purchasing info records it would be also possible to check available supply sources or preliminary variant calculation. What is important, in the variant model there is a possibility to interfere into a predefined list of BOM's elements or routing's elements. It is a very desirable functionality for DMKs, as the product ordered by the customer may differ from the one available in variant configuration by a small component only, non-existent in the system, such as a drain of untypical diameter. Such a material can be included in the BOM at the sales order level. Configuration of DMK at this level results in:

- creating a dynamic bill of materials for DMK on the basis of super BOM + changes made 'manually';

- creating a dynamic task list (routing) for DMK.

Objects defined in such a way are then a basis for the MRP run and planning in accordance with the adopted planning strategy. Variant configuration enables adopting very flexible planning strategies. As the analysis in part 1 shows, in the case of DMKs make to stock production is not generally practiced, but it is desirable to store certain inventories of raw materials and components (assemblies) due to reproducibility in kits. Thus, an especially interesting are planning strategies for the second and the following BOM levels, without the need for planning the demand for DMKs. Such strategies (for example the standard for such cases strategy 25 for DMKs and 70 for assemblies, or an exceptionally interesting combination of strategy 89 for DMK and 70 for assemblies) function in such a way that the planned independent requirements (that is for instance, the volumes planned in SOP or SAP APO) are entered at the level of raw materials and components, triggering production orders or purchase requisitions. At the moment of creating a finished product's (DMK) sales order, a BOM for DMK is dynamically created, as well as its explosion and consumption (by generating dependent requirements in MRP run) of the planned volumes for assemblies. As mentioned before, a noteworthy element at this stage is the combination of the 89 and 70 strategies. In a variant configuration that combination relieves planners from generating independent requirements for components (which is necessary in the 25 and 70 combination). Planning strategy 89, which is characteristic based, generates inactive planned independent requirements for DMKs (thus it could be said that the planner makes a kind of preparation for making DMK sales forecasts). The inactive dependent requirements for components are determined next, which could be activated using a transfer report. The dependent requirements for assemblies are created depending on the frequency of using certain characteristics in DMKs. Thus there is a possibility to plan demand for assemblies more accurately, whereas their consumption occurs, like in the 25/70 combination, after generating an order for DMKs. 
It is also worth noting that variant configuration enables quick generation of a constant variant (which means, for example a DMK whose sales are regular and are thus worth planning) on the basis of configurable material. It ten receives its own material number.

The last property of the desired implementations on an IT platform is the possibility to make quick changes in production schedules and the material requirements and orders related to them, as well as generating scenarios. The problem here is the time necessary to execute a MRP run, which is a serious limitation with a high number of raw materials and assemblies. It seems, however, that the problem can be solved by migrating to database technologies optimized in terms of processing large amounts of data, simplifying the data model (eliminating table redundancy) and implementing in-memory architecture. The solution which to some extent breaks the previously existing time barriers while performing typical operational transactions (such as planning material requirements) is the ERP SAP S/4 HANA class system based on SAP HANA platform. In particular, servicing the supply chain in terms of managing resources and planning and production execution is characterized by a significant speed in this solution. Thanks to combining OLTP and OLAP scenario analyses are available on this platform at the transaction's level. For example, the MRP run may be executed in almost real time, and in addition it is possible to simulate planning decisions, as well as generate scenario recommendations for the user within MRP transaction6. A more detailed comparative presentation of this solution's functionality, even in terms of the PP module, greatly exceeds the scope of this article, yet in the context of product groups such as DMKs the possibilities of modern IT technology must be considered. It seems that other vendors of ERP class systems will soon join in with their offers in this segment.

\section{Conclusion}

It seems true to claim that the implementation in the ERP II system environment and the variant model solves a significant part of problems with proper servicing of supply chains for DMKs. It guarantees:

- one source of truth;

- effective transfer of information, minimizing the time devoted to internal business processes, more resources devoted to customer service;

- simple defining DMKs at the sales order level;

- checking variant availability (whether components exist);

- checking actual availability of DMKs and assemblies;

- the possibility of quick price estimation of DMK variant (integration with cost calculation);

- document control;

- generating DMKs from beyond the available variants;

\footnotetext{
${ }^{6}$ More information on SAP S/4 HANA system to be found on SAP (2016).
} 
- generating dynamic BOMs and routings;

- elimination of data redundancy and the necessity of maintaining many thousands of separate DMK master data records;

- quick and precise transfer of information to MRP, and further along the supply chain;

- possibility of planning on the basis of using the characteristics, at the component level;

The article has pointed to the characteristic features of DMK product group supply chain in the context of certain proposals of IT solutions which can improve the servicing of the chain's selected links. In particular, attention was drawn to the need for virtualization of information (implementation of at least SD, PP and MM modules of ERP class system), outstanding adequacy of variant configuration as product model and the CTO type production model related to it. The article referred to those details of variant configuration which best correlate with the actual parameters of the DMK group. It also pointed to the emerging technological possibilities in terms of improving the reaction time of the material requirement planning and the next links if the supply chain (planning and launching production and purchases), which are of special importance for the DMK group. One can point path for further research in the topic such as better econometric models for sales / production forecasting for DMK and applications of Industry 4.0 concept in a production model.

\section{References}

Adamczewski, P. (2007). Ku inteligencji biznesowej w systemach ERP II. In S. Kozielski, B. Małysiak, P. Kasprowski, \& D. Mrozek (Eds.), Bazy Danych: Nowe Technologie. Warszawa: Wydawnictwo Komunikacji i Łączności.

Akhtar, J. (2013). Production planning and control with SAP ERP. Boston: Galileo Press.

Auksztol, J., Balwierz, P., \& Chomuszko, M. (2012). SAP. Zrozumieć system ERP. Warszawa: PWN.

Banaszak, Z., Kłos, S., \& Mleczko, J. (2011). Zintegrowane systemy zarządzania. Warszawa: PWE.

Barlow, J., Childerhouse, P., Gann, D., Hong-Minh, S., Naim, M., \& Ozaki, R. (2003). Choice and delivery in housebuilding: lessons from Japan for UK house-builders. Building Research and Information, 31(2). doi:10.1080/09613210302003.

Blumöhr, U., Münch, M., Ukalovic, M. (2012). Variant Configuration with SAP. Boston: Galileo Press Inc.

Chandra, C., \& Kamrani, A.K. (2004). Mass customization: a supply chain approach. New York: Springer. doi:10.1007/978-1-4419-9015-0. 
Comstock, M., Johansen, K., \& Winroth, M. (2004). From mass production to mass customization: enabling perspectives from the Swedish mobile telephone industry. Production Planning \& Control, 15(4). doi:10.1080/0953728 042000238836.

Da Silveira, G., Borenstein, D., \& Fogliatto, F.S. (2001). Mass customization: Literature review and research directions. International Journal of Production Economics, 72(1). doi:10.1016/s0925-5273(00)00079-7.

Davis, S. M. (1989). From 'future perfect': Mass customizing. Planning Review, 17(2). doi:10.1108/eb054249.

Forza, C., \& Salvador, F. (2002). Managing for variety in the order acquisition and fulfilment process: The contribution of product configuration systems. International Journal of Production Economics, 76(1). doi:10.1016/ s0925-5273(01)00157-8.

Frazell, E. (2002). Supply Chain Strategy: The Logistics of Supply Chain Management. New York: McGraw-Hill, doi:10.1036/0071418172.

Helo, P.T., Xu, Q.L., Kyllönen, S.J., \& Jiao, R.J. (2010). Integrated Vehicle Configuration System - Connecting the domains of mass customization. Computers in Industry, 61(1). doi:10.1016/j.compind.2009.07.006.

McIntosh, R.I., Matthews, J., Mullineux, G., \& Medland, A.J. (2010). Late customisation: issues of mass customisation in the food industry. International Journal of Production Research, 48(6). doi:10.1080/00207540802577938.

Parker, P.M. (2008). The 2009-2014 World Outlook for Surgical and Medical Instruments. Retrieved 30.12.2016 from http://bookfi.net.

Partanen, J., \& Haapasalo, H. (2004). Fast production for order fulfillment: Implementing mass customization in electronics industry. International Journal of Production Economics, 90(2). doi:10.1016/s0925-5273(03)00214-7.

Pine, B.J., Victor, B., \& Boynton, A.C. (1993). Making mass customization work. Harvard Business Review, 71 (5).

SAP. (2016). Retrieved 30.12.2016 from https://scn.sap.com.

Simha, R.M., \& Word J. (2012). Integrated Business Processes with ERP Systems. Hoboken: John Wiley and Sons.

Szkoda M. (2010). Zintegrowane systemy informatyczne w logistyce - SAP R/3. Kraków: Politechnika Krakowska.

Tseng, M.M., \& Jiao J. (1996). Design for Mass customization. CIRP Annals Manufacturing Technology, 45(1)/1996.

U.S. Census Bureau. (2016). Retrieved 30.12.2016 from http://www.census. gov.

Waters, D. (2015). Zarządzanie operacyjne. Warszawa: PWN.

\section{Acknowledgements}

Author contributions: author have given approval to the final version of the article. 


\section{Appendix}

Picture 1.

Disposable Medical Kit

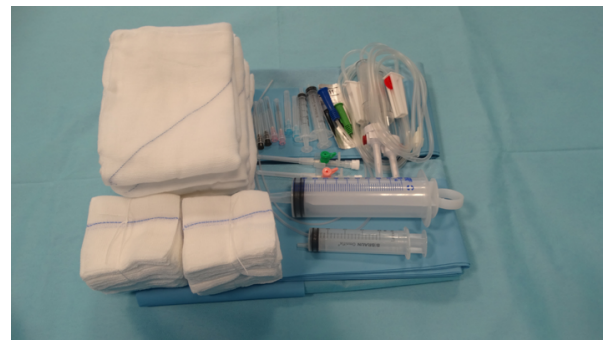

Source: Manufacturer's catalogue.

Picture 2.

An example of preparing DMK characteristic

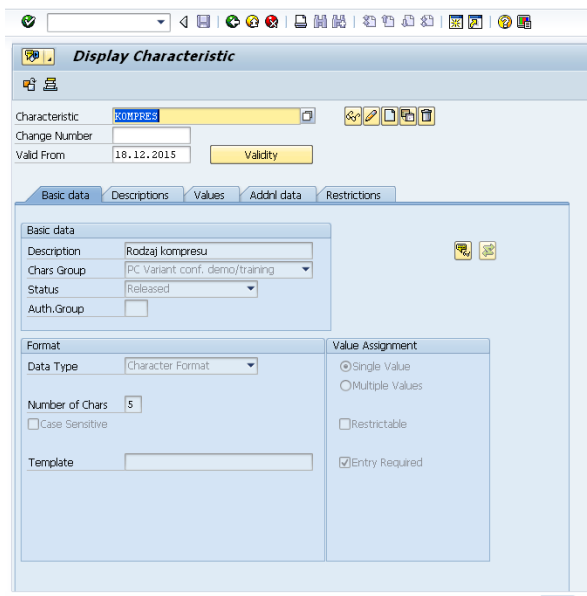

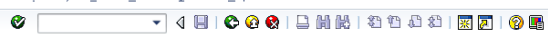

鹤, KOMPRES

\section{ERKCMPRES}

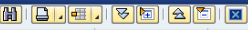

Diplay Hierachy Descripticn Defalt Object Deps TG Gazowy b

GRI Rozmlar I

- 目 P2 Podtyp 2

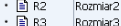

- 祭 GRTG Gazowy z nitką RTG

Source: own preparation. 
Picture 3.

An example of preparing a DMK class

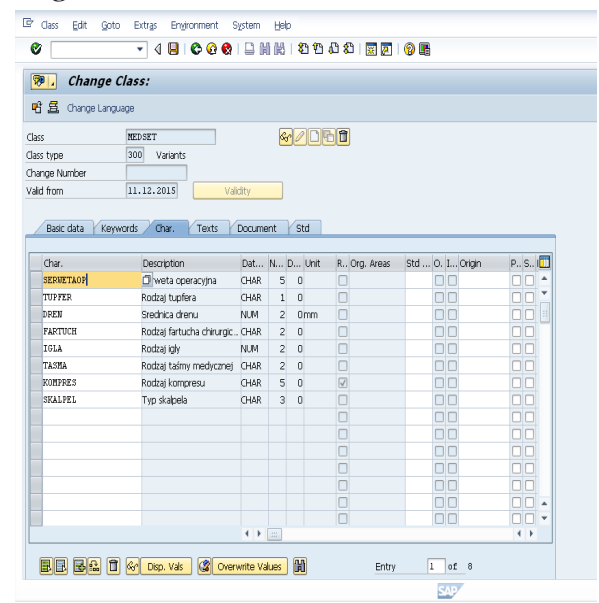

Source: own preparation.

\section{Picture 4.}

\section{Maintaining master data of configurable DMK material (1)}

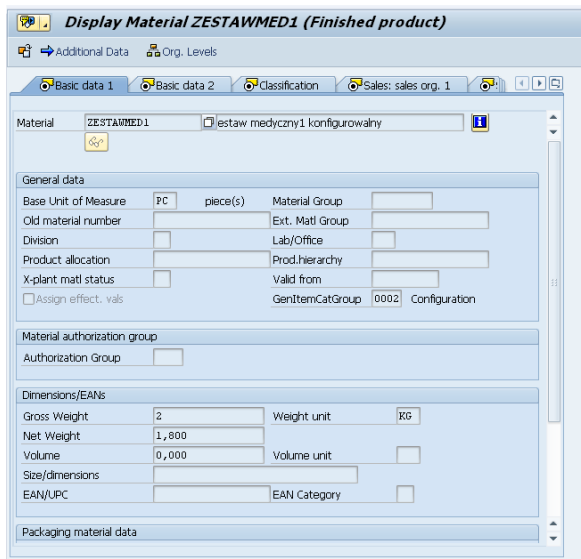

[isplay Material ZESTAWMED1 (Finished product) 惯 $\Rightarrow$ Additicnal Data 品Org, Levels

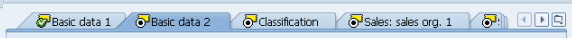

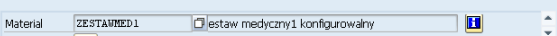

Other Data

Prod.,irsp. memo $\square$ ind. Std Desc.

Page format

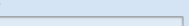

DG ndicato profle $\square$ Q Exiranmentally flut

DG Packaging Status $\square$ पIn bukkliquid

DHohly yiscous

Design documents assigned

VINo link

Design Drawing

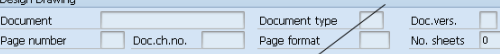

Cllent-spezlitc configuration

Crass-plant CM

Source: own preparation. 


\section{Picture 5.}

Maintaining master data of configurable DMK material (2)

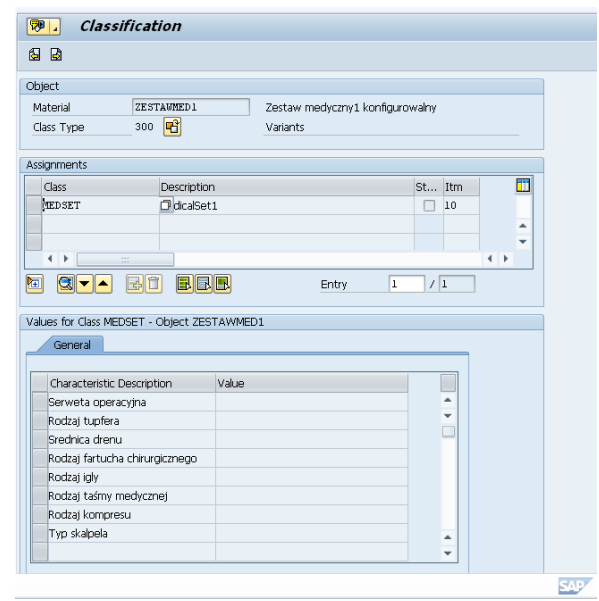

Source: own preparation.

\section{Picture 6.}

\section{Maintaining master data of configurable DMK material (3)}

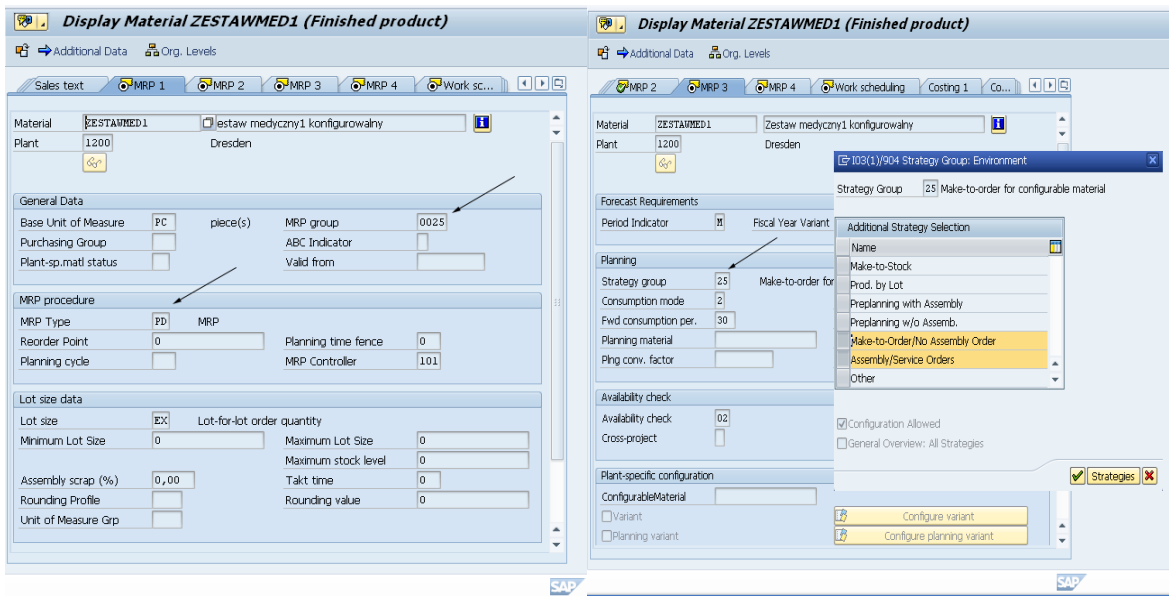

Source: own preparation. 


\section{Picture 7.}

Variant configuration at the level of customer's order

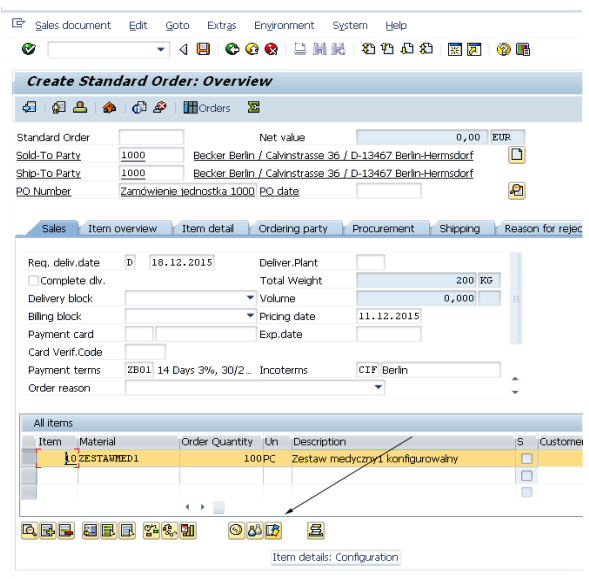

Source: own preparation.

\section{Scheme 1 .}

\section{Integration of supply chain (SD-PP-MM)}

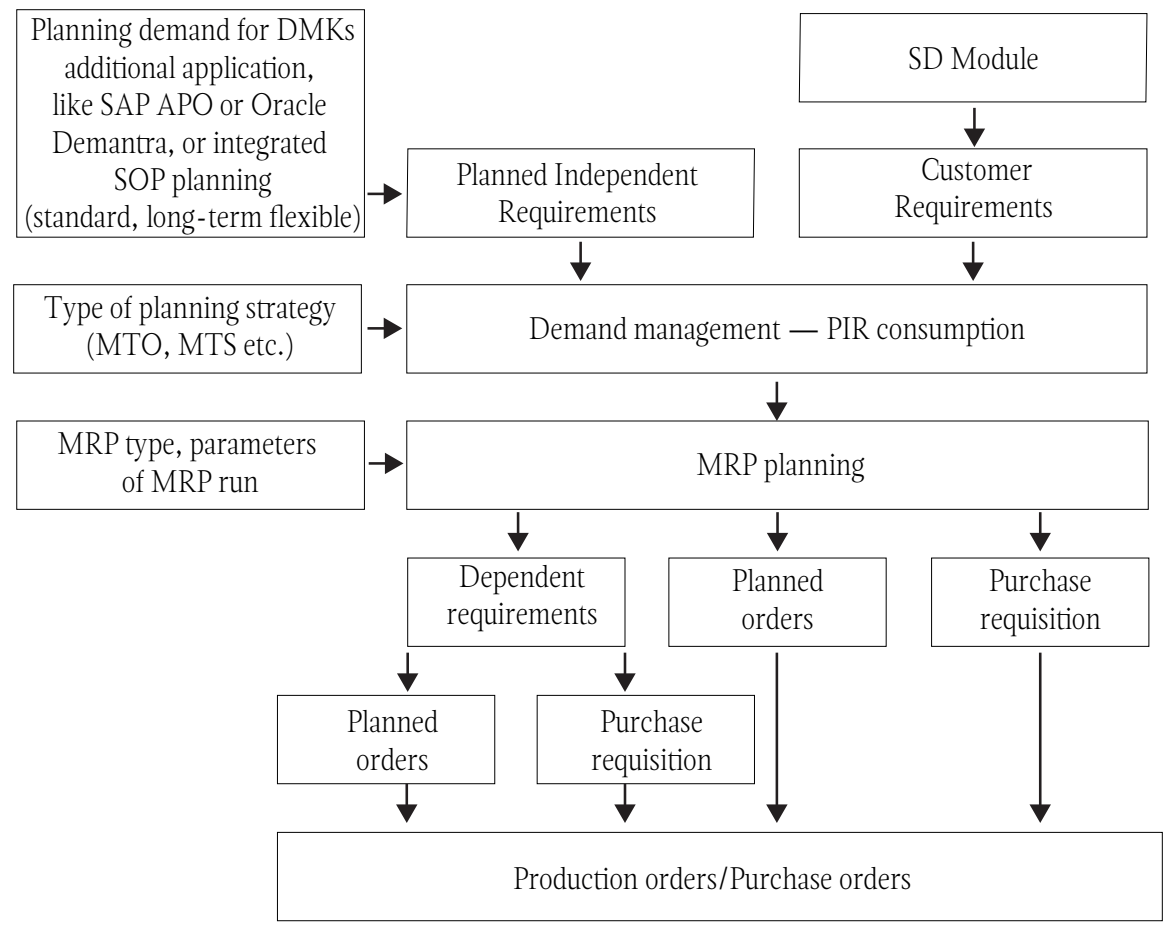

Source: own study on the basis of Akhtar (2013, p. 531). 